\title{
Using Games-Based Learning: How it Influences the Learning Experience and Outcomes of Primary School Children
}

\author{
http://dx.doi.org/10.3991/ijet.v8iS2.2782 \\ Aishah Abdul Razak and Thomas M. Connolly \\ University of the West of Scotland, UK
}

\begin{abstract}
Under the new Curriculum for Excellence (CfE), teachers at schools across Scotland are encouraged to use constructivist learning approaches that promote challenge and enjoyment in learning. One of them is through the use of games-based learning (GBL) technologies in classroom education, where the students are not only expected to learn by playing computer games, but also creating computer games. Two teacher surveys were conducted across primary schools in two separate regions in the West of Scotland to identify how GBL is being implemented within primary schools. The results showed that the use of GBL, especially the game making approach, was very limited. Following the surveys, several school-based field works were conducted to identify and compare the learning experience and outcomes from the teachers' and students' perspectives when using GBL and non-GBL (the traditional) approaches. This paper summarizes the result of one case study conducted at one primary school in Scotland. The participants were the teacher and her students in Primary 4 level. They were exposed to learning times tables using two different approaches, one using computer games and the other one without the use of computer games. The findings have shown that the learning outcome is slightly better when using computer games. However, in terms of the learning experience, the teacher's pedagogical style has a great influence on the students' preferences and enjoyment in learning for both approaches. Overall, the findings have strengthened the fact that using computer games does not eliminate the role of the teacher. To maximize the potential of a GBL approach, more training and exposure to GBL are needed to help the teachers increase their understanding and capacity in using this approach. With proper support from the teacher, GBL can make learning more engaging, provide better learning outcomes and make the process of learning less tedious.
\end{abstract}

Index Terms-Computers for education; games based learning; human computer interaction; teacher and students experience

\section{INTRODUCTION}

In Scotland, the Scottish Government has made radical changes in its education policy by introducing a new curriculum known as Curriculum for Excellence (CfE). This transformation of education in Scotland aims to provide a coherent, more flexible and enriched curriculum from nursery up to Secondary level. The aims are to prepare young people for an ever changing world and nurture them to be successful learners, confident individuals, responsible citizens and effective contributors. Unlike the previous curriculum, CfE focuses more on context rather than content with the child at the centre of the learning process to achieve optimum engagement. This new curriculum promotes active learning, by encouraging young people to think, question, research and work together rather than being passively fed information as in a traditional learning approach such as lectures and classroom instruction. One of the teaching approaches emphasized under this new curriculum is games-based learning (GBL) because it can promote challenge and enjoyment in children's learning. Within the CfE, GBL is used not only through playing game, but also pupils are encouraged to create games, which is listed as one of the experiences and outcomes to be achieved at primary school level. To promote the use of GBL for teaching and learning, a GBL initiative called The Consolarium is set up to provide the platform for the teachers across Scotland to explore a range of computer games and game making tools and share their experience on how the appropriate use of computer games can have a positive impact on teaching and learning. In addition, it can also offer training and technical support and loan a range of game based resources that include games and consoles for example, Nintendo Wii, Nintendo DS, Sony PS3 and Xbox 360. It is claimed that a range of games-based technologies are now being used in classrooms throughout Scotland to help make teaching and learning experiences challenging, demanding and appealing.

\section{A. Definition and learning theory supporting $G B L$}

According to Tang, Hanneghan and El Rhalibi [1], GBL is an innovative learning approach derived from the use of computer games that possess educational value or different kinds of software applications that use games for learning and education purposes such as learning support, teaching enhancement, assessment and evaluation of learners. Kafai [2] discussed two perspectives of learning namely instructionist and constructionist with respects to games for learning. Most educational game such as Math Blaster is developed on instructionist theory and embedded school-like exercises in a computer game. In learning through game play using this instructional game, all actions in the game play are aimed at transmitting knowledge to the student. By applying this approach, the learner (player) is regarded as "the passive recipient of instruction" [3].

In contrast, constructionism regards learning as a process in which the learner actively constructs his or her knowledge by interacting with the subject matter. The constructionist perspective puts game making/design in the hands of children to encourage knowledge-in-use 
through developing physical or digital objects [4]. In the game making approach, the role of the computer, in this case the game creation tool, is to support such an activity by providing an appropriate environment. Constructivist learning involves students drawing their own conclusions through creative experimentation and the making of social objects. Kafai [2] suggested that constructionists have focused their efforts on providing students with greater opportunities to construct their own games and to construct new relationships with knowledge in the process, rather than embedding 'lessons' directly in games.

\section{B. Research on $G B L$}

\section{1) Learning through game play}

Johnson [5] cited in [6] viewed learning by playing games as a process of constant practice and interaction in progressively more challenging tasks through which players gradually reveal underlying sets and systems of rules. The players are engaged in a learning activity through narrative or storylines of the game they are playing. Research on the potential of using games in formal education is showing promising results. Among the findings of these studies are game playing can increase motivation and engagement with learning [7], support the development of strategic thinking, communication, negotiation, data handling [8], help in understanding between content, process and context of a subject matter [9] and trigger deep learning [10].

An example of research on game play in Scotland is the study conducted by Robertson and Miller [11] involving 634 primary 6 children (approximately ages 9-11) in 32 schools across Scotland using Nintendo's Dr Kawashima's Brain training. The study found at least $50 \%$ improvement in children's computational accuracy school based field work approach was used after playing the game for 10 weeks.

\section{2) Learning through game making}

The idea of learning through game making was initiated by Papert [12] where students learning mathematics used a programming tool called Logo to tell a 'turtle' (essentially a robot with a pen) what to do by using mathematically programmed directions. Papert argued that learning is most effective when part of an activity the learner experiences as constructing a meaningful product. Findings from research on game making point out some benefits such as enhancing problem solving skills [13], fostering creativity [14] and ability to learn programming skills [15].

An example of research on game making in Scotland within the context of CfE is presented in [16]. This paper presents qualitative results from an eight week exploratory field study in which a class of ten year olds made their own computer games using Neverwinter Nights software. The results show that game making provides a range of opportunities for successful learning to occur such as the children in this study were motivated and enthusiastic; they showed determination to achieve and were able to learn collaboratively and alone; and they also showed evidence of being able to link and apply their learning to new situations.

\section{THE STUDY}

This research investigates how GBL is being used at primary schools in Scotland within the CfE. First, to gauge the current implementation of this approach, two online teacher surveys were conducted across two separate regions in the west of Scotland. The links to the surveys were distributed to a total of 205 primary schools and 104 teachers participated in the survey. Overall, these surveys have found that the use of GBL for teaching within the $\mathrm{CfE}$ is still limited. The most popular approach to GBL is learning by playing computer games while only a minority of teachers use learning by game making. The main motivation for the teachers to use GBL was because the students enjoyed using computer games. Despite positive attitudes towards GBL, teachers lack of skills and training in using this approach limits their capacity and confidence in using this approach. Detail findings of the surveys are discussed in [17] and [18].

The next stage is to explore the experience and outcomes of using GBL approach from both teacher and students' perspective and to compare the findings with the non-GBL approach. For this purpose, a case study approach was selected to answer the following research questions:

a) How confident is the teacher in using GBL as the teaching approach?

b) How do the students respond-are they motivated and engaged during the class?

c) What are the learning outcomes and how are they assessed?

From the previous surveys, teachers with experience in using GBL approach were identified and approached. After some discussions with the teachers who have volunteered to participate in this research, only two teachers from two different schools were chosen for the field work case study. The selection was based on the suitability of time and school location and the use of GBL approach within the selected school term. Both selected teachers have used GBL approach for teaching before but using different tools (i.e. one teacher used online games and the other used console games). In the following sections, this paper will discuss in detail one of the conducted case study involving only one of the teacher and one scenario.

\section{Case Study Detail}

\section{A. Data Collection}

\section{1) Participant}

The main participants of this case study were the teacher and the students. The teacher was a female teacher aged between 41-50 years old. She has been using GBL for teaching for few years mostly for learning support such as using some games from Education City Website with the Primary 4-6 students. Although she was happy in using the approach and admitted that the students really enjoyed it, she has never used computer games as the main approach in teaching a topic and was quite skeptical in the potential.

The students were 28 (13M, 15F) Primary 4 students aged between (7-8 years old), from mixed ethnicity background. The teacher has known the student quite well and has noted that they were mostly less able students that need a lot of supports from the teacher.

\section{2) Procedure}

At the beginning of the Term 3 of 2011/2012, the researcher met with the teacher to discuss the teaching plan 
and select some sessions throughout the term for observation. All the sessions were conducted in a computer lab, which was divided into two areas next to each other. One area was equipped with 18 individual PCs and the other area was equipped with 1 smart board and several tables and chairs arranged in groups. Prior to the start of data collection, the researcher joined the teachers in some classes to get familiar with the student and establish rapport.

\section{3) Methods and Instruments}

Detail methods and instruments used for the data collection are presented below:

1. Pre-test and Post-test: The test questions were prepared by the teacher and were given to the student at the beginning and the end of every session.

2. Observation: During the selected session, the researcher observed the classroom environment and take note on the students' engagement on the task. There was no video recording to be made as it requires written consent from the parent. If any of the parents does not give consent, it will be a problem because the observation was done during normal class hour which would involve all students in the class.

3. Log sheet: At the end of each session, the student were given a $\log$ sheet to complete where they were required to state what they think they have learnt, did they enjoy the class and why, and also whether they want to do the activity again next time. To rate the enjoyment, the students were requested to state whether they have enjoyed the class or not using the fun measurement toolkit shown in Fig. 1. If they have enjoyed the class, they were to circle the smileys to rate their enjoyment. The more smileys circled, the higher the enjoyment rating.

Another version of the fun measurement toolkit used was shown in Fig. 2, which was a modified version of The Fun Semantic Differential Scale (FSDS) [19]. Two versions of fun measurement toolkits were used because the students involved in this research were quite young, around 7-8 years old. By using two different measurements, the results can be compared and it would be possible to find out which toolkit is more suitable for that age group and reduce the risk of using the unsuitable toolkit. However, only one version was used at a time with the second version only used at a later stage of the observation.

The teacher was also given a log sheet at the end of the session to know how she thought the lessons went and how she felt the children in the class performed in these lessons. The input from the log sheets were compared to the notes from researcher's observation to ensure consistency and reliability.

4. Interview: Few students were identified with the help from the teacher to capture their views and challenges in using GBL and non-GBL for learning. The interview was carried out randomly and informally at the end of any session. Interviews with the teacher were also conducted randomly through out the term to evaluate teachers' opinions and expectations on the learning topic. The findings were compared with the teaching log sheet collected at the end of each class to identify any gap/ inconsistencies.

All submissions at the end of each activity and assessments record prepared by the teacher through out the term were collected and analyzed to evaluate the students' progress and learning outcomes using GBL and non-GBL approaches.

\section{B. Scenario background and session arrangement}

The subject involved for this class was Mathematics with the topic times tables involving 1-7 times tables. The learning objective was that the children should be able to use their times tables to solve Mathematics problems. The experience and outcomes according to the CfE guideline in Numeracy and Mathematics that suit this objective is given in Table I.

As the GBL approach required the use of computers, it was decided that the sessions were to be conducted at the computer laboratory. There were only 18 computers in the lab, which was not sufficient for all 28 students in the class. For that reason, the students were divided into two groups with group A consisting of 14 students (7M, 7F) and group B consisting of 14 students $(6 \mathrm{M}, 8 \mathrm{~F})$. Initially, there were eight one-hour sessions identified throughout the term. However, due to unavoidable circumstances, only six sessions were observed. The first four sessions ran consecutively every week, and then they had a two weeks break

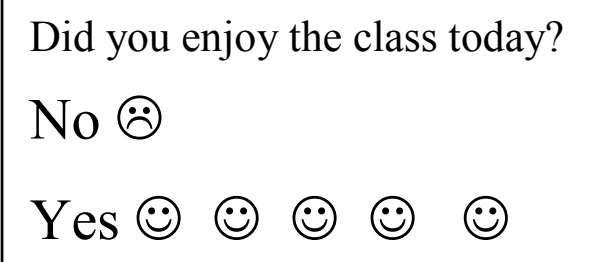

Figure 1. The Fun toolkit to measure fun version 1.

TABLE I.

THE EXPERIENCE AND OUTCOMES ACCORDING TO THE CFE GUIDELINES.

\begin{tabular}{|l|l|l|}
\hline $\begin{array}{c}\text { Curriculum } \\
\text { Area }\end{array}$ & \multicolumn{1}{|c|}{ Experience and Outcomes } & \multicolumn{1}{c|}{ Code } \\
\hline $\begin{array}{l}\text { Numeracy and } \\
\text { Mathematics }\end{array}$ & $\begin{array}{l}\text { I can use multiplication when solv- } \\
\text { ing problems, making best use of } \\
\text { the mental strategies and written } \\
\text { skills I have developed. }\end{array}$ & \\
\hline
\end{tabular}

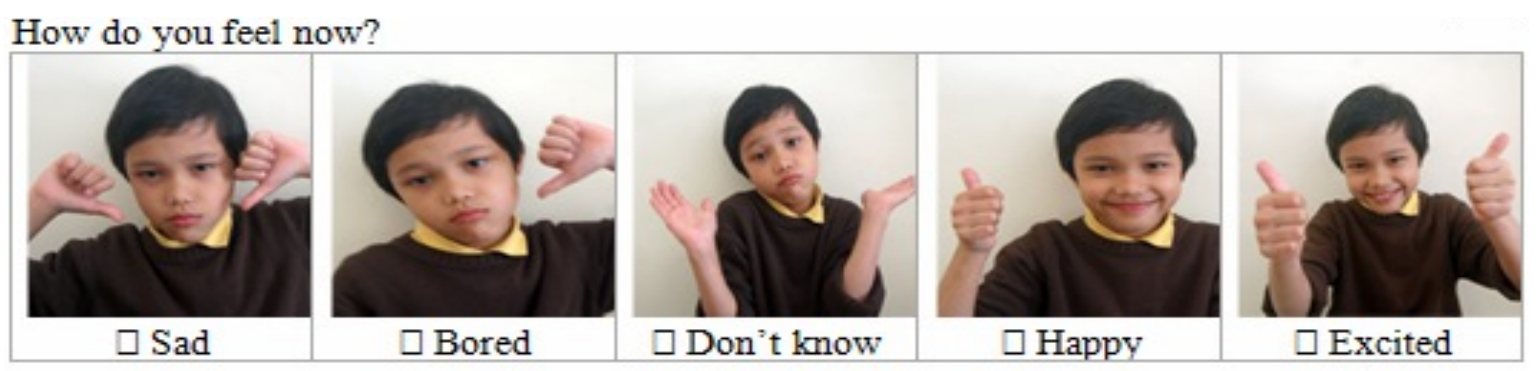

Figure 2. The Fun Semantic Differential Scale (FSDS) to measure fun version 2. 
before having another two sessions in two consecutive weeks. In each session, one group learnt using the GBL approach while the other group learnt using the non-GBL approach. The learning approach for each group was reversed every session and this arrangement continued for the whole six sessions. This arrangement was adopted to give a fair chance for each group to explore both approaches and to give feedback and preference on both approaches at the end of the term. As there were two groups involved in one session, a teacher assistant was invited to help the teacher with one of the groups together with the researcher. In the first four sessions, the teacher handled the non-GBL group, while the teacher assistant and the researcher handled the GBL group. After that, the role was reversed. This arrangement was used so that each group would have the chance to learn using GBL and non-GBL approaches with the teacher and the teacher also had the chance to experience and give feedback on both approaches. Table II gives the arrangement for each group for the six sessions.

The session structure is shown in Table III. In each session, before the lesson began, the students were given a pre test for 10 minutes. Then each student will get into their group and learn using the selected approach for that group for 30 minutes. This was followed by another 10 minutes of post test. About 5 minutes were reserved at the start of the class for setting up the computer and 5 minutes at the end of the class for discussion. The pre test and post test questions were prepared by the teacher and consist of a series of times tables to complete. For the first three sessions, the test consisted of 30 questions from 2 to 6 times tables. For the rest three sessions, the test was upgraded to include 7 times tables, giving a total of 36 questions.

The details of the GBL and non-GBL approach are discussed below.

\section{1) GBL approach}

Two GBL approaches were selected for this scenario. The first one was learning through game play. For this purpose, the student practiced their times tables by playing interactive times tables games that are available on a Math Zone website (http://www.woodlandsjunior.kent.sch.uk/maths/timestable/interactive.htm).

There were about 30 interactive games to choose from and all the games were for single player.

The second one was learning through game making. The students and teacher had never tried game making before and were not familiar with any game making software. To investigate the response of students and teacher to game making, it was decided to use a simple game, developed using power point called Space Decoder, which is available for download at uncw.edu/EdGames website. The Space Decoder game is a simple space based drill and practice game for single player. The power point game was selected because:

- both teachers and students were familiar with the power point software;

- the game template is available for download and can be used immediately for editing and playing without the need to install new software;
- the game is built to load quickly, is visually appealing and fun, and runs on average specification computers;

- the game is trademark free and copyright clear.

During the game making activity, the students were expected to create questions with answer choices using a given template. In general, the game template has been modified to include two levels. The first level, the students were expected to create some straightforward multiplication questions and give a set of answer selection, with one correct answer among them. In the next level, the question were in the form of problem solving where the students were expected to create a problem that needs multiplication and also provide a set of answer selection. Fig 3. shows some snapshots of the game template showing level 1 and level 2 question example.

TABLE II.

GROUP ARRANGEMENT THROUGH OUT THE TERM.

\begin{tabular}{|c|c|c|c|c|c|c|}
\hline Session & $\mathbf{1}$ & $\mathbf{2}$ & $\mathbf{3}$ & $\mathbf{4}$ & $\mathbf{5}$ & $\mathbf{6}$ \\
\hline A & $\begin{array}{c}\text { Non- } \\
\text { GBL }\end{array}$ & GBL & $\begin{array}{c}\text { Non- } \\
\text { GBL }\end{array}$ & GBL & $\begin{array}{c}\text { Non- } \\
\text { GBL }\end{array}$ & GBL \\
\hline B & GBL & $\begin{array}{l}\text { Non- } \\
\text { GBL }\end{array}$ & GBL & $\begin{array}{c}\text { Non- } \\
\text { GBL }\end{array}$ & GBL & $\begin{array}{c}\text { Non- } \\
\text { GBL }\end{array}$ \\
\hline Teacher & \multicolumn{3}{|c|}{ Non-GBL group } & \multicolumn{3}{c|}{ GBL group } \\
\hline
\end{tabular}

TABLE III.

SESSION STRUCTURE.

\begin{tabular}{|c|l|}
\hline Time & \multicolumn{1}{|c|}{ Activity } \\
\hline 5 minutes & Setting up the computer \\
\hline 10 minutes & Pre-test \\
\hline 30 minutes & Learning using GBL/non GBL \\
\hline 10 minutes & Post-test \\
\hline 5 minutes & Discussion/ Completing the log \\
\hline \multicolumn{2}{|c|}{ Total $=60$ minutes } \\
\hline
\end{tabular}

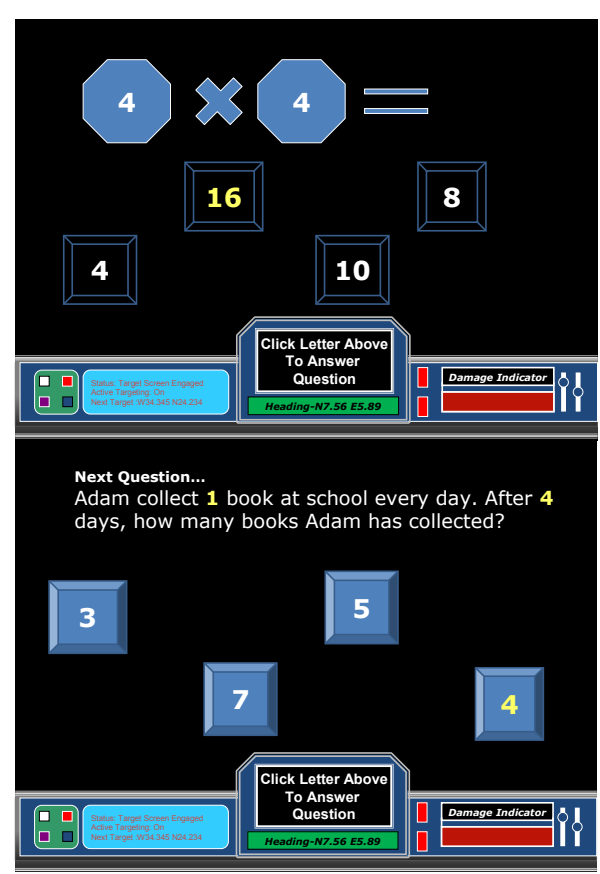

Figure 3. Snapshots of the game template 
As game making was something new to both the teacher and students, it was not made compulsory for the students to try it during the GBL session. During the GBL learning approach, the students were required to play the game on the website. The researcher will then approach some students and ask them if they would like to try making their own game. If they agreed, then the researcher will show them the space decoder game and give some explanation on how to modify the questions and answer in the game using the template. After that it was left to the students to make their own game themselves. At the end of the session, all games produced by the students were saved according to the date for evaluation.

\section{2) Non-GBL approach}

The non-GBL approach used the traditional approach to learning times tables. In the first four sessions, the students practiced times tables together with the teacher through active learning and peer tutoring. Example of activities included testing each other by writing on each other's back, quiz where the teacher give an answer and the students come out with a question and chanting the tables where one student give the question and the other give the answer. For the last two sessions, only peer tutoring were used as the teacher was in charged of the GBL group.

\section{FINDINGS}

\section{A. Teaching/Learning Experience}

\section{1) Teacher}

Based on the observations, the teacher was very motivated during the first four sessions when handling the non-GBL approach group. The teacher noted that the students were more manageable as it was just half the original class and they were located together within a small area. The teacher seemed to enjoy practicing times tables with the students, asking questions and interacting with them. However, occasionally, the teacher was quite distracted when students from the other group interrupted when having problems with other students or with the computers. During the last two sessions, the teacher took over the GBL approach group. It was observed that the teacher was not as motivated as in the previous approach. The students were dispersed across a larger area of the classroom and engaged with the computer. The teacher seemed to be less involved with the students, allowing them to work on their own without much interaction or teaching. In addition, as it was the final two weeks before the term end, the teacher seemed to be quite busy with other school activity and there were some interruptions from outside the class that needed the teacher's attention.

From the interviews and log, the teacher preferred the non-GBL approach for teaching times tables because she enjoyed teaching in smaller groups and directly delivering the teaching rather that using the computer to deliver it. She felt that non-GBL was easier as she can adopt her teaching according to students' needs and have direct interaction with them. The teacher preferred to use GBL purely as learning support within a short time, for example to summarize a topic and to quickly check students' understanding at the end of a lesson. She did not like the idea of spending a lot of time on the computer because she thought it was not good for social development. She believed that the computer can be a very useful tool but it is very addictive and can be harmful if it is not used for the right purpose. She strongly believed that it is very important to have credible research that supports the efficiency of learning by playing computer game before fully adopting this approach.

In terms of game making, the teacher felt that it was a more useful aspect of the GBL approach because it was very engaging, involved learning new skills, more interactive and creative and the students can learn how games are made rather than just playing them. However, she believed that this approach was under utilized because it was time consuming to set up in the first place. The teachers need to be proficient in using the game creation tool themselves, which might require some new skills before they can teach the students. Moreover, teachers may not have the opportunity to learn all those skills during school time due to time constraints, thus they would have to learn these skills in their own time. Unless the teacher has a personal interest in game making, it would be quite a challenging approach to adopt.

\section{2) Students}

For the GBL group, it was observed that the environment seemed to be calmer and quieter. In all sessions, within the first 5 minutes, the students would have settled into the Math Zone website and started exploring the games. As time passed, two categories of students were observed. The first category was the students who were progressing well with the game. This group of students was engaged with the learning and enjoyed playing and scoring the Maths game. The second group of students was less engaged with the game and some students in this group were not progressing well. Upon detailed observation, most of these students were having difficulties understanding the question/game and could not answer almost all questions correctly. As a result, they became bored easily and started moving from one game to another game without completing them. In some cases, they even drifted away from the times tables exercise and engaged in unrelated games or even moved to a wrong website. Sometimes the teacher's assistant sat with some students in this category and helped them to progress. However, not much improvement was observed as there was only one assistant and there were many students requiring attention.

The game making activity within the GBL group also received mixed responses from the students. When the researcher approached some students and introduced them to the game making activity, it has captured the interest of other students to try it too. However, as they were required to explore the game themselves, only a few have made significant progress in creating the game. Most of them managed to get about halfway and then return to the game playing activity or engaged in another task. Few students were identified to be particularly interested in this activity and made good progress. This particular group of students even remembered to continue working on the game during their next turn in the GBL group. The students that have successfully created a game were encouraged to ask their friend to test the game. During one session, one student was very excited when she completed her game and kept asking everybody including the teacher to try her game. This motivated many students in that group to try making their own game too. However, that student was so excited about the game she made that she could not concentrate on the post-test at the end of the session and failed to complete it. Another observation made was that some students were more interested on the design aspects of the game, for example, changing the font colour, 
background, shape, rather than focusing on the learning aspects of the game, namely making the questions and answer for the game. This group of students has created visually attractive games but with no educational content that reflected on the times tables.

For the non-GBL group, in general the students seemed to be engaged with learning in all sessions. This was because the teacher was actively observing and ensuring that the students participated in the activity. The students in this group were seated around a large table and it was very easy for the teacher to monitor their activity and keep them engaged.

Table IV showed the enjoyment rating on a scale of 1-5 achieved at the end of each session. The result has shown that both enjoyment rating and again rating for GBL and non-GBL group were very similar to each group.

In terms of attitudes towards computer games, all but two students stated that they enjoyed playing computer games. On a likert scale of 1 (sad) to 5 (excited), the average rating given for the feeling when playing computer games was 4 indicating a high level of happiness. However, most of them felt that learning times tables by playing computer games was harder than practicing with friends and teacher.

When the students were asked about what they think the best way to learn times table, the result has shown that $39 \%$ of them preferred to combine both approaches; followed by $32 \%$ preferred GBL and $29 \%$ preferred learning with the teacher. Among the reasons given for the choice are:

- Both

'More games help me learn'

'It is fun to practice with a friend'

'It helps me learn'

- GBL

'I like to make my own game it is fun'

'fun, entertaining, learnt better'

'I know my times table'

'the computer is more fun'

\section{B. Learning outcomes}

The learning outcomes specified in Table 1 were assessed using several methods, namely through the test score, teacher's own assessment and the output of the game designed by the students from the game making activity.

Table V shows the descriptive statistic on the average score achieved by the GBL and non-GBL group in all six sessions. The result indicated that students have made some improvement in the post test for both approaches, with GBL approach made a slightly higher gain. To check whether the difference in the post-test and pre-test for GBL and non-GBL approach is statistically significant, a paired sample t-test with one tailed test was used. The t- statistic was used because, in this case, the sample size was less than 30 . The result has shown that both differences were not statistically significant $(\mathrm{GBL}, \mathrm{p}=0.06$, non-GBL $\mathrm{p}=0.37$ ). One important observation during the post-test was that some students in the GBL session were more reluctant to stop their activity on the computer whether they were playing games, making a game or engaged on another unrelated task on the computer when the learning period ended. Because of the addiction to the computer, they did not concentrated on the post-test that was run directly after the learning period ended. Considering this evidence, it might suggest that the students from the GBL group might have gained better in the post-test had they concentrated more on the test.

Based on the teacher's professional judgement on the overall student achievement throughout the sessions, she felt that the students had not performed very well. As mentioned earlier, the students were mostly less able students that required a lot of support from the teacher. Due to the group arrangement, some students, especially those in the GBL group, might not have got the attention they needed from the teacher. However, the teacher was surprised to see that the test scores showed that the GBL group performed slightly better compared to the non-GBL group.

In the case of the game making output, the findings were limited because it was not compulsory for all students. Thus, the assessment was only performed on the collected games completed by the students who were interested to try this approach. In total 21 games were saved throughout the six sessions, however, only 14 games were evaluated because 7 of the games were made by the same student, and only the most completed ones were included. Table VI shows the grade given to the collected games made by students.

TABLE IV.

ENJOYMENT RATING AND AGAIN RATING FOR GBL AND NON-GBL SESSION

\begin{tabular}{|c|c|c|c|c|}
\cline { 2 - 5 } \multicolumn{1}{c|}{} & \multicolumn{2}{c|}{ GBL } & \multicolumn{2}{c|}{ Non-GBL } \\
\cline { 2 - 5 } & Enjoyment & Again & Enjoyment & Again \\
Rating & Rating & Rating & Rating \\
& $(1-5)$ & $0-N o$, & $(1-5)$ & $0-N o$, \\
& $1-$ Don't & & $1-$ Don't \\
& & know \\
& $(\mathrm{mean} / \mathrm{sd})$ & know & $($ mean/sd $)$ & $2-$ Yes \\
& & $2-Y$ es & & $(\mathrm{mean} / \mathrm{sd})$ \\
\hline Average & $4.15 / 1.265$ & $1.73 / 0.665$ & $4.13 / 1.338$ & $1.82 / 0.343$ \\
\hline
\end{tabular}

TABLE V.

DESCRIPTIVE STATISTIC OF THE TEST RESULT

\begin{tabular}{llllll}
\hline Group & $\begin{array}{c}\text { Test } \\
\text { time }\end{array}$ & Mean & SD & $\begin{array}{c}\text { SD } \\
\text { error }\end{array}$ & $\begin{array}{l}\text { Difference in } \\
\text { Pre/Post test }\end{array}$ \\
\hline GBL & Pre test & 16.79 & 10.55 & 1.99 & 1.66 \\
& Post test & 18.45 & 11.13 & 2.10 & \\
\hline Non- & Pre test & 19.43 & 10.30 & 1.95 & 0.42 \\
GBL & Post test & 19.86 & 8.60 & 1.62 & \\
\hline
\end{tabular}

TABLE VI.

ASSESSMENT ON THE GAME CREATED BY STUDENT

\begin{tabular}{|l|c|}
\hline \multicolumn{1}{|c|}{ Grade } & $\begin{array}{c}\text { No of Students/ } \\
\text { game }\end{array}$ \\
\hline $\begin{array}{l}\text { A- Completed both levels, the game was tested by } \\
\text { some friends }\end{array}$ & 3 \\
\hline $\begin{array}{l}\text { B- Completed Level 1, showed some understand- } \\
\text { ing on the game making concept but need more } \\
\text { time to complete the game }\end{array}$ & 3 \\
\hline $\begin{array}{l}\text { C- Has not completed any level but showed some } \\
\text { understanding on the game making concept and } \\
\text { times table }\end{array}$ & 2 \\
\hline D- Tried but no progress shown & 6 \\
\hline
\end{tabular}




\section{DISCUSSION}

In this case study, the students were divided into two groups, where each group learnt using a different approach (GBL or non-GBL) alternately. In the actual learning environment, this arrangement might be suitable when the students in the class have different levels of learning ability, where one group needs more attention from the teacher than the other group that can learn independently.

The students' test scores suggested that GBL has not brought significant achievement to the students; however, the teacher has noted that she was surprised to see that the students' performance during the GBL sessions was better than she expected especially from the aspect of game making achievement. One possible reason for this was lack of involvement by the teacher. Often, it was observed that most students were stuck after a period of time and started to get bored and moved to other website. As mentioned earlier, students in this scenario were mostly less able students that required a lot of support from the teacher. Unfortunately, the teacher was not motivated to use the GBL approach over a long period of time and did not play an active role in monitoring the students as in the non-GBL session.

It should be noted that the result of the test only represents one aspect of the learning outcomes specified in Table 1 namely how well the students memorized the times tables and improved their written skills. The wider aspect of the learning outcomes was demonstrated in the game making activity. However, the limitation of this case study was that the game making aspect was not widely explored due to the students' and teacher's lack of knowledge and familiarity with this approach and limited time and human resource to help with this activity. Another advantage for the students under the GBL approach was that the students playing the computer games were exposed to a wider variety of multiplication games, which involved answering straight forward multiplication questions, and also problem solving, which required the students to test their mental strategies and apply their knowledge to solve the questions. Compared to the non-GBL approach, the activities mostly involved the students memorizing the tables. Unfortunately, in this study students' scores on the computer games were not analyzed in detail, which has limited the findings on student achievement.

In terms of motivation, perceptions, attitudes and preference, the teacher preferred using the non-GBL approach. She perceived learning as best when the student interacts with the teachers compared to the computer because it enables personalization according to student's needs. She did not enjoy the GBL approach as it involved less direct teaching and she found it harder to monitor the students. The teacher was very motivated when using the non-GBL approach, interacting with the students and closely monitoring the students' progress, making sure that everybody was engaged on the task. She played a less active role during the GBL session and letting the students explore the games themselves without much intervention. Although the teacher perceived game making as a better way to learn compared to game playing, she did not actively participate in the students' game making activities as she was not familiar with it. The students on the other hand, showed a mixed preference over the GBL and non-GBL approaches. Although most of them enjoyed playing computer games, many believed that learning would be best if they were helped by the teacher and friends.

In general, the findings from this study suggested that the main driving influence of children's learning is the teacher's pedagogical style as emphasized in [20]. A study on the use of GBL in Scotland [21] found that some teachers were anxious and concerned about using computer games in their teaching and learning. Among the concerns raised by the teachers were fear in trying something new particularly in using games that they were not already familiar with. They felt insecure and sometimes worried that children would be distracted by games rather than learning from them. These concerns demonstrated that many teachers have not been properly exposed to the idea of GBL. It should be recognize that the skills and knowledge to adapt this approach does not always come intuitively and teachers need support in understanding how GBL can be used effectively [6]. Besides providing the necessary training on GBL, the school can also implement some central strategies that promote successful use of the GBL approach in the classroom. These include providing sufficient teacher support (technical and resources), allowing flexibility in timetabling and lesson organization to give teachers the time to explore the full potential of working with games over longer periods of time and promoting a larger culture of collaboration by encouraging collaboration with professional peers, as well as providing the means to facilitate this [22].

\section{CONCLUSION}

Overall, the findings from this case study emphasized the role of the teacher in making the GBL approach successful. Many studies have shown that the use of ICT can increase motivation and student performance $[23,24]$; however, this does not eliminate the role of the teacher to actively monitor and guide the student towards the learning objective, as they do when there is no ICT involved. When properly used, GBL has the potential to enhance teacher-children communication and rapport, encourage inventiveness and mutual sharing of information, and can make the process of learning less tedious [25]. Another important finding from this case study was the importance of the game making aspect of GBL in maximizing the learning outcomes. This approach was currently under utilized due to the lack of skill and confidence of the teacher to use this approach. Clearly, more training on GBL is needed especially during pre-service education to give the teachers exposure to this approach and increase their understanding and capacity in using GBL, especially the game making approach.

\section{ACKNOWLEDGMENT}

This paper is a scientific publication as part of the Games and Learning Alliance (GaLA). GaLA is a Network of Excellence on 'serious games' funded by the European Union in FP7 - IST ICT, Technology Enhanced Learning (see http://www.galanoe.eu). GaLA gathers the cutting-edge European research and development organizations on 'serious games', involving 31 partners from 14 countries. The University of the West of Scotland is one of the partners.

\section{REFERENCES}

[1] S. Tang, M. Hanneghan, and A. E. Rhalibi, "Introduction to GamesBased Learning," in Games-Based Learning Advancements for MultiSensory Human Computer Interfaces: Techniques and Effective 
Practices, L. B. Mark Stansfield, Thomas Connolly, Ed., ed: IGI Global, 2009, pp. 1-77.

[2] Y. B. Kafai, "Playing and Making Games for Learning: Instructionist and Constructionist Perspectives for Game Studies," Games and Culture, vol. 1, pp. 36-40, 2006. http://dx.doi.org/10.1177/1555412005281767

[3] T. C. Reeves, "Interactive learning systems as mindtools," in In P. Newhouse \& . (Eds.), Viewpoints 2, ed, 1993, pp. 2--11.

[4] S. Papert, Ed., Situating Construction (Constructionism Norwood, NJ: Ablex Publishing, 1991, p.`pp. Pages.

[5] S. Johnson, Everything Bad is Good for You: How Popular Culture is Making us Smarter. London: Allen Lane/Penguin, 2005.

[6] R. Sandford and B. Williamson, "Games and Learning: A handbook from Futurelab," Futurelab2005.

[7] T. W. Malone and M. R. Lepper, "Making learning fun: A taxonomy of intrinsic motivations for learning," in Conative and affective process analysis. vol. 3, R. E. Snow and M. J. Farr, Eds., ed Hillsdale, NJ: Lawrence Erlbaum, 1987, pp. 223253.

[8] J. Kirriemuir and A. McFarlane, "Literature Review in Games and Learning," Bristol2004.

[9] J. H. G. Klabbers, "The gaming landscape: a taxonomy for classifying games and simulations," Digital Games Research Association Digra, pp. 54-67, 2003.

[10] J. P. Gee, "What Video games Have to teach Us about Learning and Literacy," ACM Computers in Entertainment, vol. $1,2005$.

[11] D. Robertson and D. Miller, "Learning gains from using games consoles in primary classrooms: a randomized controlled study," Procedia - Social and Behavioral Sciences, vol. 1, pp. 1641-1644, 2009.

[12] S. Papert, Mindstorms: Children, computers and powerful ideas. . New York NewYork: Basic Books, 1980.

[13] M. H. M. Yatim and M. Masuch, "GATELOCK: a game authoring tool for children," presented at the Proceedings of the 6th international conference on Interaction design and children, Aalborg, Denmark, 2007. http://dx.doi.org/10.1145/1297277.1297318

[14] J. Robertson and K. Nicholson, "Adventure Author: A learning environment to support creative design," in Proceedings of the 6th International Conference o $n$ Interaction Design and Children, Aalborg, $\quad$ Denmark, 2007. http://dx.doi.org/10.1145/1297277.1297285

[15] Y. B. Kafai, "Software by Kids for Kids.," Commun. ACM, vol. 39, pp. 38-39, 1996. http://dx.doi.org/10.1145/227210.227221

[16] J. Robertson and C. Howells, "Computer game design: Opportunities for successful learning," Comput. Educ., vol. 50, pp. 559-578, 2008. http://dx.doi.org/10.1016/j.compedu.2007.09.020
[17] A. Razak, T. Connolly, and T. Hainey, "Teachers' Views on the Approach of Digital Games-Based Learning within the Curriculum for Excellence," International Journal of Game-Based Learning (IJGBL), vol. 2, 2012.

[18] A. A. Razak, T. M. Connolly, G. J. Baxter, T. Hainey, and A. Wilson, "The Use of Games-based Learning at Primary Education Level within the Curriculum for Excellence: A Combined Result of Two Regional Teacher Surveys," presented at the 6 th European Conference on Games-based Learning (ECGBL), Cork, Ireland, 2012.

[19] Y. M. Yusoff, I. Ruthven, and M. Landoni, "The fun semantic differential scales," presented at the Proceedings of the 10th International Conference on Interaction Design and Children, Ann Arbor, Michigan, 2011.

[20] R. E. Clark, "Reconsidering the research on learning from media," Review of Educational Research, vol. 53, pp. 445-459, 1983. http://dx.doi.org/10.3102/00346543053004445

[21] J. Groff, C. Howells, and S. Cranmer, "The impact of console games in the classroom: Evidence from schools in Scotland," ed, 2010.

[22] R. Sandford, M. Ulicsak, K. Facer, and T. Rudd. (2006). Teaching with games: using commercial off-the-shelf computer games in formal education. Retrieved from: http://www2.futurelab.org.uk/resources/documents/project_reports/te aching_with_games/TWG_report.pdf (25/1/2013)

[23] H. Bouta, S. Retalis, and F. Paraskeva, "Utilising a collaborative macro-script to enhance student engagement: A mixed method study in a 3D virtual environment," Comput. Educ., vol. 58, pp. 501-517, 2012. http://dx.doi.org/10.1016/j.compedu.2011.08.031

[24] F. Ke and B. Grabowski, "Gameplaying for maths learning: cooperative or not?," British Journal Of Educational Technology, vol. 38, pp. 249-259, 2007. http://dx.doi.org/10.1111/j.14678535.2006.00593.x

[25] D. Eggarxou and S. Psycharis, "Teaching history using a virtual reality modelling language model of Erechtheum," International Journal of Education and Development Using Information and Communication Technology (IJEDICT), vol. 3, pp. 115-121, 2007.

\section{AUTHORS}

Aishah Abdul Razak is a PhD. student at the School of Computing, University of the West of Scotland, UK (e-mail: aisya.razak@uws.ac.uk).

Thomas M. Connolly is a Professor at the School of Computing, University of the West of Scotland, UK (e-mail: thomas.connolly@uws.ac.uk).

This article is an extended and modified version of a paper presented at the EDUCON2013 conference held at Technische Universität Berlin, Berlin, Germany from March 13-15, 2013. Submitted 18 May 2013. Published as re-submitted by the authors 25 July 2013. 